\title{
Mario Filho e a "Invenção" do Jornalismo Esportivo Profissional
}

André Mendes Capraro*

\begin{abstract}
Resumo: Mario Filho é apontado como a principal referência do jornalismo esportivo brasileiro. O objetivo do presente artigo é o de investigar como foi construída a máxima de que este agente seria o "inventor" do jornalismo esportivo moderno. Seguindo alguns "indícios", principalmente a análise de crônicas esportivas, concluiu-se que foi sobretudo na cidade do Rio de Janeiro que Mario Filho se tornou uma celebridade do esporte. Por outro lado, seu alcance era limitado em outros centros. Quanto à transmissão recorrente de que o jornalista foi o "inventor" do jornalismo esportivo moderno, destaca-se a importância do reforço feito por reconhecidos jornalistas, intelectuais e artistas. No seio deste grupo, o mais engajado foi seu próprio irmão, Nelson Rodrigues.
\end{abstract}

Palavras-chave: Mario Filho; futebol brasileiro; crônica esportiva.

\section{INTRODUÇÃo}

Mario Rodrigues Filho nasceu em Recife no ano de 1908. Filho do renomado advogado e jornalista local Mario Rodrigues, conhecido pelo seu engajamento político. Era o terceiro filho dentre os quatorze que o casal Mario Rodrigues e Maria Esther teve. Em virtude de alguns problemas políticos de Mario Rodrigues, na capital de Pernambuco, a família teve que se mudar para o Rio de Janeiro, em 1916 (CASTRO, 1992, p. 11-20). Mario Filho tinha apenas oito anos de idade, portanto, foi criado na metrópole que era a Capital Federal, vivenciando, assim, aquele fenômeno que Nicolau Sevcenko (1998) definiria como o "boom esportivo" do início do século XX.

Desde jovem trabalhando em diários de propriedade da própria família, no início Mario Filho exerceu apenas funções administrativas. Logo foi encarregado de exercer o posto de jornalista responsável

\footnotetext{
*Universidade Federal do Paraná.Curitiba, PR, Brasil. E-mail: andrecapraro@onda.com.br
} 
pelo caderno literário. Porém, não demorou muito tempo para que mudasse da página de literatura para a seção de esportes. Gostava muito de fazer a cobertura do futebol e, mesmo sabendo do descrédito que esta tinha ao lado do jornalismo policial no meio jornalístico, aceitou o desafio de desenvolver tal conteúdo (ANTUNES, 2004, p. 123-124).

Mario Filho teve que prematuramente assumir a chefia da família Rodrigues após a morte do irmão mais velho Roberto e do pai Mario Rodrigues, respectivamente em 1929 e 1930. Assumiu a responsabilidade com esmero. Inclusive, tornou-se uma espécie de mentor intelectual do seu irmão mais novo, Nelson Rodrigues. Este, sem nunca perder a admiração pelo irmão/tutor e se desvincular das suas principais ideias acerca do estilo brasileiro de jogar futebol, iria, de forma intensa, principalmente após a morte de Mario Filho, divulgá-las.

Em maio de 1931, o jovem e inovador Roberto Marinho, que recém assumira a direção de $\mathrm{O}$ Globo, convidou Mario Filho para assumir o caderno de esportes do referido jornal. Aos vinte e três anos, já era considerado um veterano no desenvolvimento do jornalismo esportivo (CASTRO, 1992: 115). No mesmo ano fundou um dos primeiros jornais esportivos, O Mundo Esportivo, que teve uma breve duração (RODRIGUES, 2004, p. 44). Em 1936, com a ajuda financeira de alguns amigos - novamente com o aval e a participação direta de Roberto Marinho no negócio - tornou-se proprietário do Jornal dos Sports. Mario Filho até o final da vida, em 1966 iria exercer o posto de jornalista esportivo, proprietário e editorchefe de periódico especializado e se dedicaria arduamente ao desenvolvimento dos esportes e de outras manifestações culturais, como os desfiles de escolas de samba.

\section{UMA PROPOSTA: INVESTIGAR A "INVENÇÃO" dO JORNALISMO ESPORTIVO}

Devido a tal trajetória, os biógrafos de Mario Rodrigues Filho o apontam como uma das principais referências para o rompimento 
com o antigo modelo jornalístico que tratava dos esportes - escrita rebuscada, conteúdo frívolo e análise sob uma ótica elitista (CASTRO, 1992). Logo, tornou-se praticamente um consenso que a iniciativa de reestruturar o jornalismo esportivo foi exclusiva deste agente (RODRIGUES, 1994).

Em síntese, a ideia difundida é a de que desde o início da carreira, Mario Filho, como filho de um proprietário de jornal e também pela reconhecida capacidade jornalística e literária, optou de livre escolha pelo jornalismo esportivo - inclusive, contrariando o próprio pai (CASTRO, 1992). Assim, como trabalhar na parte de esportes não era uma necessidade, tampouco, um posto de transição, Mario Filho foi um dos jornalistas que mais se preocupou em remodelar o conservador modelo adotado nas páginas esportivas (RODRIGUES, 1994). Com a finalidade primária de melhor investigar esta hipótese amplamente difundida, o objetivo do presente artigo é, portanto, o de analisar como foi construída a máxima de que Mario Filho seria o "inventor" do jornalismo esportivo moderno.

\section{Mario Filho - SEgundo Nelson Rodrigues - um REVolucionáRio NO CAMPO JORNALÍSTICO}

"Indícios" (GINZBURG, 1996) relevantes da origem de tal ideia podem ser encontrados nas crônicas do irmão mais novo de Mario Filho, o polêmico Nelson Rodrigues. Dentre vários e vários textos que enalteciam os valores do jornalista, destaca-se uma crônica bastante emotiva, publicada pela Revista Manchete, na qual o irmão mais próximo afetivamente de Mario Filho, descreveria, recorrendo à memória, algumas iniciativas do irmão que considerava inéditas em se tratando de jornalismo esportivo, o que o caracterizaria como o "fundador" do jornalismo esportivo moderno. A primeira iniciativa, a valorização do jornalista especializado no assunto, aquele que se dedicaria exclusivamente ao esporte:

Hoje, eu e meus colegas andamos por aí, realizados, bem-sucedidos, temos automóveis e freqüentamos boates; andamos de fronte erguida e o nosso palpite 
tem a imodéstia de uma última palavra. Mas eu gostaria de perguntar: - o que era e como era a crônica esportiva antes de Mario Filho? Simplesmente não era, simplesmente não havia. Sim, a crônica esportiva estava na sua pré-história, roia pedra nas cavernas. Não vejam crueldade nas minhas palavras, mas apenas simples e exata veracidade histórica. Bem me lembro do tempo em que comecei a escrever esporte. Meu companheiro de seção era uma miserando, mais humilhado e mais ofendido do que o Marmeladov do Crime e Castigo. Quando ria, ou sorria, mostrava uma antologia de focos dentários. E os outros colegas padeciam de igual miséria dostoievskiana. Era uso, então, entre os clubes, oferecer um lanche à crônica. Nada mais plangente e pungente do que a voracidade com que agredíamos os guaranás e os sanduíches (RODRIGUES, 1994, p. 8-9).

Usando do seu inconfundível estilo dramático, Nelson atribui ao irmão a mudança do perfil do jornalista esportivo que, de um fracassado, passa repentinamente a detentor de um "capital simbólico" (BOURDIEU, 2004) significativo no campo jornalístico. Segundo o teatrólogo, Mario Filho, então, antologicamente, serviu como parâmetro para valorização dos seus próprios pares. Neste sentido, Mario Filho tinha a mesma função redentora que o selecionado brasileiro que atuou na Copa do Mundo de 1958.

A segunda iniciativa seria a de alterar abruptamente a linguagem usada nos textos jornalísticos sobre o esporte.

[...] E o pior era a linguagem estarrecedora. Mario Filho usava a palavra viva, úmida, suada. Naquele tempo, os estilistas da seção de esporte assim redigiam a notícia de um Flamengo X Fluminense: "Será levado a efeito amanhã, no aprazível field da rua Paissandu, e esperado prélio", etc. etc. E o cronista que conseguia esse nível de estilo se julgava um Proust. A entrevista de Mario Filho foi um duro impacto, sobretudo pela linguagem. [...] Dir-se-ia um novo idioma atirado na cara do leitor. O público todo teria o direito de perguntar: - "Mas que língua é essa?". Mesmo os melhores jornalistas da época 
escreviam de fraque. [...] E a simplicidade seria uma degradação para qualquer jornal (RODRIGUES, 1994, p. 9).

Nelson Rodrigues nem percebeu a incoerência no raciocínio: como poderiam jornalistas elitistas que "escreviam de fraque" e de forma rebuscada ter tão baixa auto-estima como exposto no primeiro excerto? Mas a redação mais simples e dinâmica, segundo Nelson Rodrigues, não seria a maior alteração proposta. A própria estrutura geral dos jornais foi mudada, adaptando-se aos novos requisitos do esporte, sendo, portanto, a terceira iniciativa de Mario Filho.

[...] Posso dizer que, desde então, ninguém influiu mais na imprensa brasileira. O próprio artigo de fundo deixou de ter a pose do mordomo de filme de policial inglês. Nos tópicos, fazia-se, vez por outra, uma concessão à nova língua. Em suma: - o jornal deixava de ser besta. E, graças a Mario Filho, o futebol invadiu o recinto sagrado da primeira página. [...] E, súbito, o grande jogo começou a aparecer, no alto da página, em oito colunas frenéticas. Tudo mudou, tudo: - títulos, subtítulos, legendas. Abriase a página de esporte e lá vinha o soco visual: - o crioulão do Flamengo, de alto a baixo da página. $\mathrm{E}$ não era a pose de hirta. Mario Filho acabou com o craque perfilado como se estivesse ouvindo o Hino Nacional. O craque aparecia em pleno movimento, crispado no seu esforço. E as figuras plásticas, elásticas, acrobáticas, enchiam as páginas de tensão e dramatismo. E, com isso, o diretor, o secretário e o gerente descobriram o futebol e o respectivo profissional. O cronista esportivo deixava de ser o pai da Sônia do Crime e Castigo. Começou até a mudar fisicamente. Por outro lado, seus ternos e gravatas acompanhavam a fulminante ascensão social e econômica (RODRIGUES, 1994, p. 9).

No texto-manifesto, Nelson é nitidamente tendencioso, porém tal crônica, por ter uma função explicativa, acabou referenciando alguns pontos importantes ocorridos na reforma do jornalismo esportivo. Sem dúvida, Mario Filho foi um vanguardista, mas não se pode atribuir exclusivamente a ele (como Nelson o fez) o surgimento 
da imprensa esportiva profissional. É notório que a adaptação do jornalismo esportivo transitando das colunas sociais à imprensa especializada foi um processo com a participação direta de Mario Filho, mas também de vários outros jornalistas e escritores, além de editores, proprietários, atletas e diretores, entre outros indivíduos engajados, espalhados por todo o país (TOLEDO, 2002).

\section{Influências intelectuais e aRtísticas em MaRio Filho}

Além disso, mesmo a radical mudança na forma de escrever as crônicas esportivas - que, segundo o tendencioso irmão mais novo, Nelson, "[...] fundava a nossa língua" (RODRIGUES, 1994, p. 9) -, na verdade, não era nada inédita. Como constata Ruy Castro:

[...] os vapores da Semana de 1922 já tinham se espalhado pelo Brasil e os truques mais modernosos do Modernismo - as frases curtas, os "flashes" visuais, um certo jeitinho malcriado de escrever eram uma doença entre os jovens escritores. Os modernistas eram fáceis de imitar, tanto que se imitavam uns aos outros, como Oswald de Andrade e Ronald de Carvalho, que eram os que Mario Filho, por sua vez, imitava (CASTRO, 19992, p. 112).

Mas se os modernistas eram a referência de Mario Filho no início da carreira de cronista esportivo, ao menos no tangente ao estilo da escrita, aos poucos, novas tendências artísticas, literárias, esportivas e intelectuais acabaram também sendo refletidas na sua produção. O círculo de relacionamentos de Mario Filho era amplo. Muitas personalidades de áreas variadas circulavam pelas redações de jornais nas quais Mario Filho trabalhava. Outros contatos ocorreram por meio do próprio futebol e, posteriormente, do carnaval - vale lembrar que o primeiro jornal de Mario, o Mundo Esportivo, foi o responsável pela criação dos desfiles de escolas de samba. Evidentemente, na medida em que Mario Filho conhecia pessoas de vulto, outras lhe eram apresentadas por intermédio dessas. É o caso, por exemplo, de Gilberto Freyre (que tanto iria influenciar na formulação que Mario Filho faria acerca do futebol), que foi 
apresentado por José Lins do Rego - outro literato renomado que escreveu crônicas esportivas e se envolveu diretamente com o futebol (RODRIGUES FILHO, 2003).

Nelson Rodrigues, ao contrário de José Lins do Rego e do próprio Mario Filho, não tinha uma acentuada preocupação em incorporar a teoria de Gilberto Freyre às suas crônicas. Priorizava nos seus textos conceber o esporte como drama, os campos como cenário e os jogadores, dirigentes e torcedores como atores representando o teatro da vida (MARQUES, 2000). Por outro lado, tinha um compromisso de fidelidade: era um admirador convicto do seu irmão Mario Filho, pois este, após a morte do pai, tinha assumido o papel de líder da família - "Amigos, cada geração devia ter um Mario Filho, ou seja, um homem de larga evocação homérica. E, então, eis o que aconteceria maravilhosamente: - a história de uma geração passaria a outra geração, assim como a chama do círio passa a outro círio. Mas Mario Filho morreu e não ouvimos mais os grandes cantos do futebol" (RODRIGUES, 1994, p. 174). Reforçava, assim, mesmo que indiretamente, ao adotar como padrão a concepção do irmão mais velho no tangente à presença do negro no futebol brasileiro, o ideal de "brasilidade" de Gilberto Freyre (FREYRE, 1999).

Dentre as formulações teóricas, expostas pelo pequeno grupo de cronistas que se destacaram no campo jornalístico brasileiro, especialmente no Rio de Janeiro, a maioria partiu de Mario Filho (RODRIGUES FILHO, 2003) - sempre pautado em Gilberto Freyre (FREYRE, 1964). Porém, a mais aceita e reconhecida não foi formulada pelo proprietário do Jornal dos Sports, mas sim por seu irmão, Nelson Rodrigues, que contou também com o apoio de outros cronistas e jornalistas que pertenceram ao grupo de admiradores de Mario Filho.

\section{NELSON ROdRIGUES INVENTANDO UMA TRADIÇÃo}

De tanto enaltecer o irmão, com mais contundência após a sua morte, Nelson criaria uma "tradição inventada" (HOBSBAWM; 
RANGER, 1997) envolvendo diretamente o próprio Mario Filho, o qual, segundo aquele, seria o inventor da crônica esportiva moderna.

Até que, um dia, Mario Filho apareceu. Pode-se datar o nascimento da crônica esportiva. Foi quando ele publicou uma imensa entrevista com Marcos de Mendonça. O famoso goleiro anunciava sua volta. O patético, porém, não era o fato em si, mas a sua escandalosa valorização jornalística. A matéria inundava um espaço jamais concedido ao futebol meia página! Era a época em que o esporte vivia empurrado, escorraçado para um canto da página. $\mathrm{O}$ melhor jogo do mundo não merecia mais de três linhas. [...] A entrevista de Marcos foi para nós, do esporte, uma Semana de Arte Moderna. Em meia página, Mario Filho profanou o bom gosto vigente até em jornal de modinhas. Ao mesmo tempo, fundava a nossa língua. E não foi só: - havia também no seu texto uma visão inesperada do futebol e do craque, um tratamento lírico, dramático e humorístico que ninguém usara antes. Criara-se uma distância espectral entre o futebol e o torcedor. Mario Filho tornou o leitor íntimo do fato. E, em reportagens seguintes, iria enriquecer o vocabulário da crônica com uma gíria libérrima. [...] Mas eu não vou contar tudo o que ele fez, porque esse homem não parou nunca. Com seu formidável élan promocional, trouxe para o futebol novas massas. O leitor, simples ou mal informado, pode perguntar: - "Mario Filho fez tudo?". Eis a casta e singela verdade: - fez tudo, sim, e repito: - tudo. Por sorte de parentesco, fui testemunha ocular e auditiva dessa obra colossal (RODRIGUES, 1994, p. 8-10).

Com a típica e incansável repetição, Nelson fez com que o engajado Mario Filho fosse reconhecido como o fundador de um novo modelo de jornalismo esportivo. Visivelmente ressentido com a morte do irmão, o teatrólogo exaltaria os feitos de Mario Filho, segundo ele, o maior cronista esportivo de todos os tempos - "Quem devia escrever a história do tricampeonato era Mario Filho. Só ele teria a visão homérica do maior feito do futebol brasileiro e mundial" (RODRIGUES, 1994, p. 158). Nelson contou com a colaboração de 
Armando Nogueira e até mesmo de Gilberto Freyre, entre vários outros jornalistas esportivos, para enaltecer o caráter de Mario Filho. E a reincidência desses textos valorizando o jornalista, culminaria com uma homenagem póstuma. O preito consistiu em renomear o Estádio Municipal do Rio de Janeiro, o popular Maracanã, que, passou a ser chamado oficialmente de Estádio Municipal Mario Rodrigues Filho (SÉRGIO, 2000).

\section{Os LIMITES DE UMA TRADIÇÃO INVENTADA}

Sem dúvida, homenagem de tamanha grandeza reitera que Mario Filho provocou "[...] um deslocamento no já frágil equilíbrio das forças que, por meio da imprensa, sustentavam a hegemonia das elites sobre os significados e valores do futebol" (SILVA, 2006, p. 109). Mas, mesmo sendo um dos primeiros cronistas dedicados exclusivamente ao futebol, e notoriamente um engajado no desenvolvimento esportivo do país, paralelamente em outros estados, principalmente São Paulo e Rio Grande do Sul, vários outros jornais também renovavam a forma como o esporte aparecia nas suas edições diárias. Afinal, o futebol se popularizava a "passos largos", sendo necessário aos periódicos mudar a forma como o esporte era noticiado, pois o público interessado no assunto também havia se alterado (TOLEDO, 2002, p. 160-174).

Constata-se, assim, que o alcance das ideias de Mario Filho se acentuou rapidamente, mas sua concepção de jornalismo esportivo era praticamente circunscrita ao estado do Rio de Janeiro e à região nordeste - devido as suas origens e o contato com José Lins do Rego e Gilberto Freyre, referências do movimento regionalista nordestino. Por outro lado, tinha pouca difusão em São Paulo - o jornalista de maior destaque na época era Tomaz Mazzoni (WITTER, 1996) - e nos estados da região sul. Sendo assim, o jornalista era um dos agentes mais eficazes e de forte alcance, mas, de longe, pode ser considerado o "inventor" do jornalismo especializado em esportes. 


\section{ApontaMeNTOS FINAIS}

Em caráter conclusivo: sabe-se que foi, sobretudo, no Rio de Janeiro que Mario Filho se tornou uma celebridade do esporte. Já no início dos anos 1940 era um dos jornalistas mais populares na cidade - inclusive tão assediado nos estádios quanto os próprios atletas (CASTRO, 1992, p. 222). Por outro lado, como já afirmado, seu alcance era limitado em outros centros.

Quanto à transmissão recorrente de que o jornalista foi o "inventor" do jornalismo esportivo moderno, destaca-se que na atualidade existe um debate acadêmico acerca de tal afirmativa. Alguns pesquisadores dão o crédito a Mario Filho (HELAL; SOARES; LOVISOLO, 2001), enquanto outros consideram que há um exagero em tal afirmação (SILVA, 2006, p. 32-36). Concordam tais vertentes que Mario Filho foi um dos primeiros literatos a ganhar espaço escrevendo sobre futebol nas capas dos grandes jornais brasileiros; que também foi o primeiro a prosperar editando um diário exclusivamente direcionado aos esportes; além de escrever vários livros respeitáveis versando sobre o futebol.

Mas a alcunha de "inventor" realmente se deu devido ao esforço e constante reforço por parte do seu círculo de convívio - composto, por sinal, por reconhecidos jornalistas, intelectuais e artistas; como, por exemplo, José Lins do Rego, Armando Nogueira, Gilberto Freyre e Roberto Marinho. No seio deste grupo de notáveis, o mais engajado em enaltecer as virtudes profissionais de Mario Filho foi seu próprio irmão, Nelson Rodrigues - na época, um consagrado teatrólogo e escritor. 


\begin{abstract}
Mario Filho of the "invention" and professional sports journalism

Abstract: Mario Filho is considered the main reference for Brazilian sporting journalism. The aim of this paper is to investigate how it was established the affirmation that this agent would be the "inventor" of modern sporting journalism. Following some "traces", especially the analysis of sporting chronicles, it was concluded that it was mainly in Rio de Janeiro that Mario Filho became a sport's celebrity. On the other hand, his reach was limited in other centers. Regarding the recurrent transmission that the journalist was the "inventor" of modern sporting journalism, it's important to emphasize the effort made by renowned journalists, intellectuals and artists. Within this group, the most committed was his own brother, Nelson Rodrigues.

Keywords: Mario Filho. Brazilian soccer. Sporting chronicle.
\end{abstract}

\title{
REFERÊNCIAS
}

\author{
ANTUNES, Fátima Martin Rodrigues Ferreira. "Com Brasileiro Não Há Quem \\ Possa": futebol e identidade nacional em José Lins do Rego, Mário Filho e Nelson \\ Rodrigues. São Paulo: Unesp, 2004.
}

BOURDIEU, Pierre. Coisas ditas. São Paulo: Brasiliense, 2004. 
CASTRO, Ruy. O anjo pornográfico. São Paulo: Companhia das Letras, 1992.

FREYRE, Gilberto. Casa-grande e senzala. Rio de Janeiro: Record, 1999.

GINZBURG, Carlo. Mitos emblemas sinais: morfologia e história. São Paulo: Companhia das Letras, 1996.

HELAL, Ronaldo; SOARES, Antonio Jorge; LOVISOLO, Hugo. A invenção do país do futebol: mídia, raça e idolatria. Rio de Janeiro: Mauad, 2001.

HOBSBAWM, Eric; RANGER, Terence. A invenção das tradições. Rio de Janeiro: Paz e Terra, 1997.

MARQUES, J. C. O Futebol em Nelson Rodrigues. São Paulo: Educ/Fapesp, 2000.

PREFÁCIO. In: RODRIGUES FILHO, Mario. O negro no futebol brasileiro. $2 . \mathrm{d}$. Rio de Janeiro: Civilização Brasileira, 1964.

PREFÁCIO. In: RODRIGUES FILHO, Mario. O Sapo de Arubinha: os anos de sonho do futebol brasileiro. São Paulo: Companhia das Letras, 1994.

RODRIGUES FILHO, Mario. O negro no futebol brasileiro. 4. ed. Rio de Janeiro: Mauad, 2003.

RODRIGUES, Nelson. O Baú de Nelson Rodrigues. São Paulo: Companhia das Letras, 2004.

SÉRGIO, Renato. Maracanã 50 Anos de Glória. Rio de Janeiro: Ediouro, 2000.

SEVCENKO, Nicolau. (Org.). História da vida privada no Brasil. São Paulo: Companhia das Letras, 1998. v. 3.

SILVA, Marcelino Rodrigues. Mil e uma noites de futebol: o Brasil moderno de Mário Filho. Belo Horizonte: Editora da UFMG, 2006.

TOLEDO, Luiz Henrique. Lógicas no futebol. São Paulo: Hucitec/Fapesp, 2002. WITTER, José Sebastião. Breve história do futebol brasileiro. São Paulo: FTD, 1996.

Endereço para correspondência:

André Mendes Capraro

Praça da Ucrânia, 44, apto 111.

Bigorrilho - Curitiba - Paraná

CEP: $80730-430$

Recebido em:03.08.2010

Aprovado em: 14.05.2011

Movimento, Porto Alegre, v. 17, n. 02, p. 213-224, abr/jun de 2011. 
